\title{
THE AFRICAN FEMALE WRITER AND HER CRAFT: ASPECTS OF YVONNE VERA'S PECULIAR FEMINIST VISION
}

\author{
Ifeyinwa J. Ogbazi \\ doi: http://dx.doi.org/10.4314/og.v8i1.5
}

\section{Abstract}

This paper is particularly concerned with identifying and examining some peculiar features of Yvonne Vera's literary artistry. It essentially explores the varied ways the Zimbabwean writer has articulated some aspects of her feminist viewpoint through the unique manner she crafts her novels. While drawing illustrations from especially Without a Name, Under the Tongue, Butterfly Burning and The Stone Virgins, it discusses some of their distinguishing qualities that include the nature of the writer's expression and interpretation of being. The paper also evaluates the significance of her unique craftswomanship (craftsmanship), especially with regard to understanding the nature of the African peoples and their world. It discovers that Vera celebrates the "Africanness" of the African, insisting as well on the exceptional qualities embedded in the human person and the exulted position she/he occupies in the cosmic arrangement of beings. In addition, the paper reveals that the writer believes in the sentient nature of the cosmos and in the interconnectivity of all existing entities. It, therefore, maintains that in light of these qualities (among others), Vera's feminist endeavour can rightly be branded as peculiar feminism.

\section{Introduction}

In contemporary times, and specifically within literary circles, it is no longer very easy for the reading audience to be attracted to works that have been written by novelists and other literary artists, probably, because of the complexities of modern society. Writers, therefore, take a lot of care in crafting their productions in distinguishing ways that will make them appeal to the tastes of the majority of their readers. It is an individual writer's responsibility to endeavour, while addressing the varied complex subjects of the 21st 
century, to make her/his production "express and assert itself through its own intrinsic coercive aesthetic power..." (Nwankwo, "Globalization" 40)

In the light of the above, it should be right to say that Yvonne Vera is one of African writers who has employed peculiar techniques in writing her five novels, namely: Nehanda, Without a Name, Under the Tongue, Butterfly Burning and The Stone Virgins. It is the power of her craft that gives a distinctive aesthetic stamp to her work. Even though some of her readers adjudge her work as difficult and unapproachable, her manner of writing is nevertheless the major attraction. Through her techniques, she achieves more objectivity and verisimilitude, making her novels true to life and thereby, highly realistic. They, in addition, make her work compelling since the readers are connected to both the feelings of the characters, as well as the bizarre and unfortunate circumstances in which they have been entrapped in. It is these varied aesthetic merits that this paper sets out to investigate.

\section{Yvonne Vera's Peculiar Craftswomanship}

An outstanding distinction of Vera's novels that is easily noticeable and which makes her work stand out from those of other writers is that they have all been written in heavy poetic prose which is lyrical/musical. She employs an intense poetic style. It is from her that we are able to understand that prose fiction can be approached in the way poetry is written. Consequently, one striking thing about her novels is that she had written them as if she was writing poetry, making them dense and compact. This style of hers has attracted a lot of comments from critics. For instance, Gunner and Kortenar say:

Vera's fiction is often described as 'poetic', meaning that it works by rhythm and repetition, by sensuous detail and emotional appeal, rather than by linear drive forward or character development. Criticism plausibly locates her in a feminine literary tradition that privileges the lyric and personal [...] As in lyric poetry where the speaking voice is everything there is remarkable consistency of 
stylistic register and no concession to shifting narrative points of view. (3)

Her style is suggestive of the fact that she has resorted to its use in order to make it fit into the forms of story she is telling. The novel content of her stories in many respects cannot be denied. Thus, one cannot help but say that she has to create new forms of language that would suit her subject and theme. In this respect, Bull-Christensen has this to say: "The poetic style of her writing is centred on the intimate and the momentary, and it speaks of the taboos of women's experiences from women's own perspective. In doing so Vera's novels appear to be negotiations of conditions, boundaries, and catastrophes in individual women's lives" (19). In essence, her subject and theme, account to a great extent for the dense and multilayered nature of her novels.

Another distinct method that can be discerned from Vera's work is her feminizing technique. Essentially, she employs this technique in order to underline the female perspective that she pursues. In Butterfly Burning for instance, while describing the scene where Phephelaphi aborts her baby, she deliberately chooses words that are usually associated with women. Such effeminate words and phrases include: "the nylon petticoat" (120), "the lace spreading along the hem, and the elastic gathering the nylon into pretty pink frills that glisten, shimmer, cupped in her hand" (Emphasis mine) 121-122). What Vera has done is to clothe an outrageous act with some elements of beauty. On the surface, it may seem as if the writer is underrating or circumventing the monstrous nature of the act. But what indeed she has subverted is the lofty language often associated with tragedy. She has resorted to the use of ordinary language, and as such, beyond these simple words used in her detailed and evocative description of her protagonist's heinous act, she succeeds in making us understand that this is certainly an uncommon deed. Equally, through the vivid image of the scene which she creates, she enables us to share in the attendant pains and trauma which Phephelaphi undergoes in the process of aborting her baby. With regard to this, Vera explains in an interview: 
I want you to be a witness, which means taking part in what is happening each moment, as it happens. But I want to do it without crudity, with a certain elegance, so you feel you can still endure it and see beauty in it. And this beauty can only be in the language, I don't see where else it can lie. That's where language becomes important. ("Interview" 222/223)

It is not a surprise that Liz Gunner and Neil Ten Kortenaar could agree that "the novels, after Nehanda, all feature infanticide, rape, abortion, or suicide, "'even though the violence is [also] heavily aestheticized.' They go on, in some instances her prose forces attention to the body in the finest, extended detail" (3). It is in fact within the elegance of her language that she entwines the crudity of the actions of the wicked actions of her characters. Thus, in a subtle manner, she gets her readers emotionally trapped in the scenes she evokes.

An additional aspect of Vera's narrative strategy which can be illustrated with this same scene - the abortion scene - is the issue of pacing. In the cause of making many elaborate descriptions, the writer employs, sometimes, a ridiculous slow pace and ultimately exerts on her readers a high degree of patience that is compulsory. The readers must fall in line with her gradual pace and be patient with her in order to get to the heart of the matter. We have to follow her pace as she delineates her suffuse descriptions. As regards Vera's representation of this scene, Grace Musila comments:

Vera keeps our eyes glued to the scene for ten pages, literally going through every detail of the feeling and texture of the process, riding the numbing waves of pain with Phephelaphi [...] In this sustained gaze on Phephelaphi's slow and painful abortion as it takes place, Vera systematically unveils not only the act and experience of abortion but also the female body which is often wrapped under the tongue of cultural 
conventions that closet it in a dark shroud of shame and silence. (56)

We equally find such cautious and elaborate details in the serialization of such scenes as Mazvita's killing of her child (Without a Name) and Phephelaphi's self-immolation (Butterfly Burning). It is in this way that she gives us the opportunity to get connected with the experiences of her characters. These descriptions also suggest the writer's underlying intention of compelling, in a rather forceful manner to take in all the details she is offering us so that we would be able to identify with the plight of her characters. She also makes us have a feel of the prevailing atmosphere by immersing us within it. Through these ways, she establishes an intimacy between the reader and the private experiences of her characters. She equally accentuates the plights of these characters by inducing pity and generosity in judgment in the reader.

Interwoven in this demand made by Vera's pace are other indirect compulsions that are the characteristic features of her novels. They pertain to "waiting", "pausing" and "expecting". The very first line of Butterfly Burning begins this way: "There is a pause. An expectation" (3). Under the Tongue ends: “...they had waited" (234). Hence, in the final analysis, it is evident that Vera often tries to elicit these actions from her readers - we have to wait, we have to pause, and we have to be expectant in order to get to the core, and these are usually the sore and crucial points she is leading us into and which she invariably demands that we experience with her characters.

It is important to draw our attention, at this juncture, to what constitute the crucial points in Vera's work. Her crucial points make reference to significant annihilating times in the lives of her female characters. What she does is that she often identifies an initial site of pain, a crucial point of pain. She then captures this particular vital moment in the life of a protagonist, and then proceeds to weave a story around it. Ruth Lavelle reveals:

In an interview with Eva Hunter (1998), Yvonne Vera explains that what inspires her to write a story is an intense emotional moment that a character 
could experience; the history of this moment becomes the subject of the story - the moment leads [Vera] into the entire world of the book.(109)

This vital moment may be the point in time when a character is being raped or being killed as we find in The Stone Virgins, or a moment when a mother is strangulating her child (Without a Name). It could also be the moment when a father rapes his daughter (Under the Tongue). In an interview illustrating this aspect of her style with Butterfly Burning, Vera explains:

This moment, frozen like that, is so powerful that I can't lose a sight of it, visually or emotionally. From it I develop the whole story, the whole novel: how do we get to this moment when the mother does this? Everything ripples around that, the story grows out of the image. I don't even have the story at the beginning. I have only this cataclysmic moment, this shocking, painful moment, at once familiar and horrifying because of one change of detail which makes everything else tragic. For me, an entire history is contained in such a moment. ("Interview", 219)

In fact, the ability to capture the moment, focusing on the point where it really hurts, is one of Vera's exclusive techniques. In four of her subsequent novels, after Nehanda, her predominant strategy has been to beam her creative lens on a crucial moment, on that destructive moment when both a woman's body and her sexuality are being violated. What makes up for the rest of the story is the exploration of the inherent implications of this violation. For instance, in Under the Tongue, we are brought to this intense, sordid moment of pain in this manner:

A hand dark and heavy descends over my face, over my eyes, tightens round my neck. My legs are crushed. My stomach is hard like rock. He enters. I cry into the night but my cry returns to me and 
spreads down into my stomach like water, water, at the bottom of the leaves, water, water beneath rock, water, water beneath rock, water, water between my legs, water (227).

As we can observe, it is towards the end of the story that Vera makes this explicit exposure. It is also towards this end that the weight of the wounded protagonist's pain is shown. Even when we get to know that it is an incestuous act that has precipitated the entire story, since it had taken place ab initio, before the story begins, Vera in this case refrains from making explicit the cause of her heroine's trauma. For the greater part of the novel, she only leads us into Zhizha's consciousness as she disgorges her feelings. The author initially explores in great detail the consequences of an unmentioned incident. It is as if she, the writer, is actually at pains herself; that is, she is experiencing some difficulty in revealing to us the cause of her protagonist's predicament. She equally wants to prepare us adequately, psychologically and otherwise, to enable us to witness this most bizarre and demeaning of human behaviour. Implicit in all of these is that what she is preparing us to witness calls for cautious observation, critical scrutiny and objective evaluation.

Where Vera excels and makes a glaring distinctive mark as a writer is in her employment of the technique of psychological realism. Psychological realism, an approach adopted by some contemporary writers and popularized by Henry James, followed by other such modernist writers as James Joyce and Virginia Woolf, is a technique, in which emphasis is not on the event. There is an undermining of the externals with emphasis on the internal action the examination of the complex workings of the human mind. Pointedly, it probes the human consciousness. The approach incorporates the stream of consciousness technique which is essentially its extension. It also adopts the interior monologue and uses a great deal of flashbacks.

Vera's adoption of this technique can be seen primarily in her Under the Tongue. First, we find that the narrative sequence is not clearly illustrated, giving the impression of no defined narrative structure. Although generally, it might be right to say that Vera is an outlaw when it comes to the rules of form and content, we cannot 
help but say that for her plot or incident is not the main issue. The pertinent issue lies with the exploration, in particular of her female characters' emotional disposition, and the relevance of this condition to their overall development. The centres of her narrative are therefore squarely domiciled within the consciousness of these characters, which is the major reason why we find that Under the Tongue highlights principally interior characterization. It is essentially an investigation into the consciousness of the major character Zhizha with a greater percentage of the entire novel focusing on her thought processes and dwelling on her consciousness. It is in this manner that this character is made realistic.

In this novel, therefore, we find that an external action has been carried out; Zhizha has been raped by her father. The action constitutes the major external event of the story. Thus, what Vera does is to develop this external deed throughout the rest of the novel by exploring the circumstances of the action, and in a more prominent manner, zeroes in on the interior action(s) which it has erupted in the sub-consciousness of the character. The writer's major concern is on the dire consequences of her female protagonist's bizarre experience; that is, the complexity of the way her mind, her whole being reacts to this unwholesome experience. In the exploration of her dilemma, the writer plumbs into the depths of the victims traumatized psyche in order to expose her inner turmoil. Hence, she lays bare Zhizha's thought processes; what Carolyn Martin Shaw terms "exteriorization of internal monologues" (25), thus allowing us to have an insight into Zhizha's turbulent mind. With much emphasis, she depicts the emotional trauma of the character by, particularly, resorting to her personal memories. The protagonist's present condition is portrayed through flashbacks and reminiscences as the writer takes us to and fro, (with regard to time), prodding us further and further into the consciousness of this wounded being.

It should be pointed out that Vera does not only zero in on a primary site of pain in the life of a particular protagonist, she also addresses the concomitant complications that often emanate from existing social conditions. For example, while Zhizha's violation by her father comprises the primary site of pain, it is the patriarchal set- 
up mainly, coupled with the restrictive colonial order and the prevailing oppressive postcolonial structures and attitudes, that not only conspire to compound and heighten the intensity of the pains already generated, but also produces other sites that are equally traumatic. The cutting of Zhizha's tongue is a case in point. As a result, her plight is aggravated further by her inability to speak. Her suffering ultimately becomes more complex.

In Butterfly Burning, apart from the point of pain when Phephelaphi performs a crude abortion on herself, the author leads us further into a more devastating cycle of pain towards the end of the novel. It is the crowning site which ultimately consumes and at the same time liberates her major character. As she dies through immolation, we are told that "as she lets go she feels nothing except her wings folding. With a bird landing and closing its wings" (151). Here her death is portrayed as a redeeming factor, Eva Hunter explains:

Thus, Phephelaphi's self-abortion and selfimmolation in Butterfly Burning, which are described in passages replete with both repetition (that suggests ritual and profundity) and with images that evoke transcendence (flying, wings, purification) may be read as an achieved act of protest and self-assertion. ('War Victims and Survivors')

It is in such ways that the author heightens emotional power and increases not only the depth and sadness that accompany these calamitous experiences, but also the extent of their tragic nature. Furthermore, Vera consistently employs silence in a symbolic manner to depict the numerous unspoken horrifying experiences of people, particularly the women. As far as she is concerned, silence, that state of voicelessness, is the major inhibiting cardinal index of the country that has accrued from many decades of terror of both colonial rule and post-independence disorder.

At this point, it is necessary to bring us to another pertinent issue that should be highlighted concerning the significant role Vera ascribes to the act of remembering. She believes that it is essentially 
the ability to remember that brings about a healing; that re-members, re-constitutes - a kind of stitching together the already dismembered female body. Martin Shaw states categorically that the "protagonists in all Vera's novels suffer some form of bodily distortion or disassociation and psychic disintegration" (32). Samuelson goes further to say that the women's recovery stems from REMEMBERING. She explains:

The violated, dismembered female body moves to the centre of the narratives as Vera's novels envisage the means by which the raped body can find recovery. The recovery and reconstitution of the body itself is located in the act of re-membering. (93)

In Without a Name, Mazvita is bound to remember the face of the man who raped her if she must recover. Her pains and torture are more profound because of her inability to remember. We are told that "she sought to discover the path she had taken toward this particular horror, but the memory hid from her. It came in flashes of a fathomless and heavy guilt" (110). The narrator informs us specifically that "she was sure that if she remembered the rapist's face, she could free herself on remembering him, she could replace his face with another with beginnings" (96). Because it is very necessary to endow tongues with strength so that they will be able "to speak the memory of their forgetting" (Under the Tongue 1), Illustrating with Butterfly Burning, Lunga highlights the point that "Memory [---] offers opportunity for flight and transcendence of limits. The urge to forget even the most recent events that define the characters in Butterfly Burning can be read as flight from, and a need to survive, life's harsh realities" (195). Thus Vera endeavours to imbue her female violated protagonists with fresh memories with which they can regain, piece together again, their violated, dismembered bodies.

One other pertinent respect in which Vera stands out from the rest is the very nature of her expression of being that is quite unique. She has interpreted experience in such an exceptional manner that no other African female writer has even done. As Chimalum Nwankwo 
points out, "Vera dwells on the sentient character of the environment in her belief that the African world is a vital, active cosmos" (50). Implicit in her representations is that the world is multi-dimensional because even the things we do not see, like the sound produced from the Kwela music is felt in such a way that the people's participation in it is so impacting on both the body and the spirit since the music possesses a potency that is so much aware to the senses. In this regard, the sound should not be perceived as a mere sound but one that constitutes an essence with a life of its own - it is endowed with its own vital force and it has a soothing effect that is healing. But unfortunately, the writer bemoans the fact that the stifling demands of modernity thwarts even the healing quality of the Kwela music.

It should be pointed out here that it is principally Vera's unique way of perception and the way she interprets phenomena that has made her use language in a peculiar way in order to interpret the African consciousness. She believes that the English language which is the colonizer's language, with its saturation of Western cultural elements and nuances, does not adequately translate the immensity and uniqueness of the African cultural world view. She therefore not only endeavours to make her language suit her ancestral background but also employs it in her own distinct way in order to interpret the peculiar experience of her people - a people grappling with the stiff demands of both the colony and the post colony. To a very large extent, for us to evaluate the material she has infused into her language in order to translate the consciousness of the African world, entails our "...looking [---] at the marriage of the ontological and the linguistic" (Nwankwo, 'To Trans-emote' 44). Chimalum Nwankwo holds strongly that:

A consciousness cannot be defined with any accuracy unless we begin with the ontological, the deep foundry where the ruling images and potent symbols of our lives are designed and forged. [---] What we should be doing more often with the language is to pursue the originating base of the translated consciousness to divine the intra-cultural or intra-national associations of expressions. ('To Trans-emote' 44). 
He further insists that it is important that the "cosmological aspects of the expression should inform on the word and its meaning" (45).

Let us briefly illustrate with the opening of Butterfly Burning which confronts us with a scene where men are scything grass at the roadside. This scene is vividly depicted by the writer in this way:

In the air is the sound of a sickle cutting grass along the roadside where black men bend their backs in the sun and hum a tune, and fume, and lullaby[...] The grass burns over the palms where they reach over and pull at it, then curve over the sickle and beyond, pull, inward, and edge the grass forward with the left palm[...] Often they manage to pull the roots out of the ground, to free something; to conquer a stubbornness; to see what is below; to touch what keeps something alive and visible. Sharp rays of the sun drop along the sharp curve, and flow along the rotating glint of the silver sickle. (emphasis mine, 3-4).

At sunset, as the men round off the day's tasking and humiliating job and "their eyes now filled with fatigue"

The grass is swishing hopeless below the shoulder, under the armpit, grazing the elbow, and its sound folds into a faint melody which dims with the slow dying of the sun, and each handful of grass becomes a violent silhouette: a stubborn shadow grasped. (5).

For Vera, what we observe going on here does not stop with the human action; it does not stop with the actions being displayed by the Zimbabwean labourers. It is true they expend a great amount of energy in the exercise, but the writer significantly draws our attention to the vegetation which is equally alive, active, animated and forceful. This explains why she makes deliberate efforts to capture the universe in its specificity, as well as give all aspects of the environment so much prominence and reverence. In this 
instance, she makes vegetation come to life. Therefore, as the grass is being cut, they just do not die. They fall like human beings, tumbling down. The description Vera makes is so acute because she wants to let us witness the extent of the life that is incorporated in them. For her, every component of the cosmos is active because it is imbued with a living force, it is energized and it is potently charged. Essentially, for her, all created things can perceive and because of the life they possess, they are all equally active participants in the cosmic activity just as human beings. Their sense perceptions combine with those of human beings and the accruing combinational powers are immense. Invariably then, we found out that, for one thing, part of Vera's major achievement is that "she imbues nature with meanings..." (25). Carolyn Martin Shaw explains that "there is nothing simple, for example, about the way she uses nature. What is consistent is the habit of assigning meaning - every natural event or living thing signifies something beyond in the world Vera creates. Nothing is simply backdrop" (26).

Hence, Vera's continuous assertion that all objects are beings constitutes a pertinent aspect that can be associated with her work. As such, she sees every aspect of phenomena - the plants, the birds, the caves, the hills, the rivers/streams, the "blue skies that beckon" (Under the Tongue, 29), as alive and active. Whereas the birds are graceful and possess power, such entities as the awe-inspiring hills of Gulati stand in awesome and intimidating splendour. The rivers/streams like the mysterious Umguza River on the other hand "is the refreshing oasis" (Chioma Opara, Her Mother's Daughter, 80) that are resplendent, assuring and life-giving. The congregating forceful marula tree binds and solidifies while the ancient caves that were the habitation of the unfathomable stone virgins serve as fortress, providing solace and offering protection, even to the morally embattled rapist Sibaso who seeks refuge there. While expressing the moral crises he is engulfed in, and wanting desperately to regain his bearing in life, this male character utilizes the cave as his spiritual anchor. In addition, the beautiful natural rural landscapes and the intriguing flowered and scented streets, such as we find in The Stone Virgins, are ascribed with enduring, soothing and vibrating qualities because of their inscrutability. 
In this respect also, Nwankwo shares Shaw's view when he says that: "To Vera the cosmos in its entirety is sentient and vibrant. All elements share in an animate kinesthesia and tactility. Every thing lives in Vera's writing. And the cosmos is as seamless as it is stitched together" (50).

Accordingly, in her belief that it is an interlocking environment, Vera is prone to summoning all cosmic authority in depicting the interconnectivity of all things. She evokes and elevates all aspects of the cosmos by clothing everything with stupendous beauty, and investing them with special authority. In the world she creates, human beings, the lands, the plants, the animals, the entire phenomena - everything in nature - all contribute to its overall working. Nothing stands on its own and nothing is excluded when it comes to active participation. Since they all possess life they are all active and they all work together. Pointedly, they all combine to make up the "active parts of the cosmos." It is the harnessing of their intrinsic qualities that unifies the phenomena. In Vera's view, the cosmos is beautiful, wholesome, integrated and very significantly, exudes and celebrates life. It is through the interrelationship between all aspects that cosmic harmony is achieved.

Another medium which Vera strongly upholds as possessing so much vital force, and from which the African is energized and made powerful is the oral culture. Consequently, in all her novels, she persistently endorses this oral culture. The vital import and transcendence of the power of spoken words over even the best crafted of human inventions is portrayed in her beautiful description of the continuous movement of people in trains to the city in Butterfly Burning. In the course of the journey in these trains, she masterfully pitches the noise made by the trains with the noise emanating from the human language:

The people have come from everywhere, and absorb and learn not only each other's secrets but each other's enigmatic language. Accent rubs against accent, word upon word, dialect upon dialect, till the restless sound clears like smoke, the collision of words, tones, rhythms, and meanings more present 
than the trains beating past. They laugh when meaning collapses under the weight of words, when word shuffles against word, but they know something previous has been discovered when a new sound is freed and soothes the gaps between them. (52-53)

What Vera is highlighting here is that of the two sounds, one clearly surpasses the other in degree and significance. Within African setting, human expression is profound, powerful, precious, and everliving. It is forceful and never decays because it encapsulates life. For these reasons, what we may deem as 'mere' words have the propensity to subdue and triumph over the thrilling music of the trains - trains that are perceived as master pieces crafted by Cecil Rhodes who represents the Western ideology.

Thus, in The Stone Virgins Vera mocks her characters who have imbibed Western mannerisms and ways of speaking, those who have clung on to nonsensical and meaningless Western clichés, and hence have alienated themselves from their people and their cultural rules. In Under the Tongue, Grandmother who is rooted in the oral tradition endeavours to apply the soothing balm to her devastated granddaughter, Zhizha, by telling her stories about the land. Vera often insists that authentic Africans are expected to be well grounded in the oral culture. They should be orators in their own rights, and be able to communicate flawlessly in the indigenous language.

Vera's view is that it is within the languages of Africa that we are able to harness the people's life force. She therefore frowns at the unfortunate development whereby colonialism has thwarted and distorted the indigenous language from which the pattern, rhythm, principles and philosophies of African life flow. She insists that, as a people, we have our own way of looking at things, our own peculiar way of interpreting the world we live in, as well as our distinct manner of expression. She therefore propagates the idea that an African language is not ordinary by its nature but a type of language that is emotively charged. It is one that embodies a potent force that is evocative and vitalizing.

She also appreciates African myths and rituals, one of the reasons why she frowns at modernity, believing that the latter has 
wrecked havoc on traditional rituals which are now seen as inhibitive and restrictive - "Rituals can be inhibiting" (Without a Name 158). The writer also believes in the spiritual and the mystical, showing how they have been embedded in humans, as we can see, in the mystical powers of Nehanda.

Vera places the human person at the apex of all creation. She maintains that the human person, including the African, (both woman and man), has been endowed with great powers that is of high value, thereby enabling them to live a more meaningful and fulfilled life. Her view also is that since both woman and man are of great worth, it is, therefore, proper and imperative for every human person to be respected.

This view can be well illustrated with Phephelaphis' selfimmolation. In this regard, the question arises: what does Vera want us to make out of this burning butterfly, and essentially, from the title of that novel? What is the essence of the fire? The study reveals that this is an extension of Vera's harping on the enormous energy which the human person (in this case, she uses the woman to illustrate this) has been invested with, as well as substantiate the idea of escape; that is, emancipation through death.

In this case, the essence of the fire is essentially energy and it's transformative nature. Indeed, the extent of the force with which Phephelaphi soars high as she burns, is in tandem with the intensity of the abundance of the power in her mind - that power that resides within her - coupled with the force of her inner longing to be free. These expose her inner active self that is in actual fact, her real being. Another aspect of this is that in this way Vera, in addition, contradicts the view that the woman is a passive being.

Moreover, Vera, through the death of her protagonist, offers her an escape of a different sort - a priceless kind of liberty which can hardly be quantified especially when it cannot be tampered with. We witness the delicate burning of the butterfly, but here the burning is not destructive since she is being changed into a higher energy that would be ultimately transformed into a higher being. In order to capture this aptly, the author chooses her words carefully, selecting those that invoke the image of transcendence such as 'wings', 'flying' and 'purification'. The concept of floating, which borders on obeying the law of buoyancy should also be noted. Phephelaphi's 
dead body floats. And we ask again: why does it float? We can say that it is only conforming to this law. In life she is over-burdened by the extreme demands of her society. At death, her body is afloat, lighter and higher, because she is now free of worries. Her life struggles are over, she has given up resistance and no longer struggling with the crushing waves which her society had generated - the forces of society that have stood against her. Having been transformed into a higher and superior energy, she can no longer be reached.

These are expressions of woman power as well as Vera's own way of stressing the view that the strength of the woman is transcendental. For her, the woman is invincible and immortal, never defeated and never dead. She is, in other words, triumphant. Vera wants us to accept that even in death the woman has still conquered the world. It is in death that she actually asserts herself, thereby fulfilling a longing that has been denied her in life.

This paper discovers that Vera has explored extensively and celebrated the "Africanness" of the African. So much is revealed by the writer's continuous harping on the essence and relevance of African consciousness. It is through this avenue that she makes Africans see the best in themselves and to understand that they are so uniquely endowed since their African background has naturally imbued them with the capacity to achieve great things. She principally affirms and endorses African humanity; the inherent humanity of the African that borders on his propensity to love, cherish and care. It is this loss of humaneness that she decries, attributing the men's many outrageous crimes to the loss of the essential humanism that is at the core of the predominant trait for which Africans are famous. It is especially in such respects that she blames them for not calling into play these essential African attributes, for not putting their innate creative power to great use in the Zimbabwean struggles. She believes that having been so gifted, so richly endowed, the merits embedded in this consciousness would have succeeded in conquering the intimidating powers of the colonizers. She frowns at the fact that the people failed to utilize these in a positive manner towards the shaping of the socio-political events of their history. It is her implicit view that the best time her people would have exploited their energy to fight for the reclamation 
of their dispossessed land was the pertinent periods of the liberation wars and post-independence crises. At those crucial periods in history, their energy, this immense strength, coupled with other endowments, would have enabled them to achieve more positive results.

It is painful to Vera that they failed to cue into the strength that accrue from traditional power, from the natural beauty of their environment and from the oneness of African communalism. This is one of the reasons why she consistently projects and advocates a collective rural consciousness, because, in the main, it is from it that the people's collective power for struggles against the invading forces would have been harnessed. She reminds them that freedom is achieved through enduring and committed struggles and not through pleas-pleading that freedom be bestowed on them. She urges them to denounce self-pity and a sentimental mental attitude. Essentially, she admonishes them for their being oblivious of their innate pride as a people from the illustrious "stone country."

In addition, and very significantly, Vera does not hide her disappointment at the people's failure to exploit the complementary strength of both man and woman that would have generated a sure victory. For her, it is not a surprise that they have not succeeded in the struggles since they have neglected the complementary crucial roles that should exist between the African woman and man.

This can rightly be adduced as one of the reasons why she seems to be advocating for complementary roles as we find in The Stone Virgins. The Stone Virgins is Vera's last novel and it may be proper to consider it as her valedictory gift. In the light of her demise, the issue of complementary co-existence between woman and man is perceived as her last wish. She clearly exemplifies what it is expected to be in the forged relationship between Nonceba and Cephas towards the closing section of the novel. In this more healthy relationship, we find reciprocal gestures, there is tolerance and respect of the other's views, of the other's feelings and self-worth. The choices made by Nonceba are respected and accommodated by Cephas. Very importantly, each person's role complements the other's. This is a crucial aspect of the female/male relationship which Vera endorses and advocates. As far as she is concerned, 
nothing is gained from male aggressiveness, authoritarianism, and sheer masculinity.

Vera subtly puts forward the view that it is limiting to depend on one particular sex since each sex needs to reinforce the other's incompleteness. For her, the human society is flawed and unwholesome because, essentially, the male sex, particularly in Africa, has failed to accept that it is incomplete without the woman. Her implied insistence is that when women are excluded from the lives of men, when they are repressed and not appreciated, when they are not given due recognition by the society, nothing works because the society concerned is already a flawed one. Any society that truly wants to develop must take into account the female experience. This is what entails the proper forward movement towards progress, towards enduring emancipation and real liberation of the African people and space. A new social order can only evolve from this balancing of roles; from this unity between woman and man.

There are other issues that are discernible in this relationship between Nonceba and Cephas through which the writer prescribes solutions to the problems that face both women and men. The scene where Nonceba rejects the job Cephas secured for her, preferring the one she has found for herself, is quite revealing. And she also refuses to lick the marula seed offered to her by Cephas. In the former, it is implied that the woman has a right of her own, that it is by accepting such favours that she comes to be abused. Added to this, Vera seems to be saying that what the woman needs is neither pity nor rehabilitation. Rather, what the society should do is to grant her an equal partnership with the man. Significantly, the right type of relationship which Vera recommends can be described as one in which "her story no longer [is] subsumed within his. So [that] it is both the bodies and the stories that are placed together, the man's and the woman's, an acknowledgement of their shared struggles to free themselves from bondage and to write their own stories of the past and the future" (77).

With regard to the other offer, Nonceba refuses to lick the seed to show that the circumstances are not yet right for her to indulge in the sweetness of the marula seed. Judging the prevailing circumstances, it is not yet necessary. The right circumstance is only 
when the woman regains her rightful position in society. It is only when this comes about that the woman can actually be free, free to assert her self-worth, free to make choices, free to create her own future and ultimately be fulfilled in life.

Another important way in which Vera excels in her work and stands apart from the rest of African feminist writers is in the mode of her engagement with patriarchy. Her pre-occupation is not with quarrelling with anybody, for she hardly engages in any gender warfare, unlike many others. What she does is to blame colonialism while equally apportioning blame to the irresponsible African leaders and the society at large. Vera blames the irresponsibility of African leaders for the creation of unpleasant conditions on the continent. She believes that it is this inimical social environment in which the people are entrapped that is primarily, responsible for eliciting their dangerous instincts.

Having being buffeted by the storms of life, her characters' demeaning behaviour and extreme actions stem mainly from the nature of their living conditions. With respect to the men, for instance, she tries to depict how their unwholesome passions and violent actions have been ignited by the existing social conditions. Therefore, she highlights various aspects of setting in order to show why the characters are behaving the way they do. As an example, she tries to illustrate how the instinct to rape a woman can come about from the prevailing environment. As if by way of hypothetical construct, Vera makes it clear that society is culpable because when people are exposed to such inhuman circumstances, they are naturally bound to behave in accordance with the nature of their existence.

It must be made clear that Vera does not maintain that it is only women who are the victims of the war. As an African feminist postcolonial writer, she takes the position that women, men and children are all part of the struggle and, therefore, are victims of those disastrous wars. Her major insistence, though, is that the quiet struggles of both the women and children are, equally, vital and significant contributions. In like manner, men like Fumbatha, Sibaso, the unnamed rapist of Without A Name, Zhizha's father of Under The Tongue, other male soldiers and the freedom fighters are all wounded beings. They have gained nothing for their struggles 
and the immense sacrifices they have made for fatherland. All they reap are betrayal, deprivation, abuse and mental torture. They, like the women and children, are victims of broken promises, dashed hopes, and unaccomplished dreams. They are all part of history, they have all been raped, they are the casualties of the cruel colonial masters and the intolerant and brutal African leaders of postindependence Zimbabwe. In essence, everyone is implicated. Everyone was involved in this collective disaster.

In light of the foregoing, the writer poignantly depicts the characters in ways that we cannot help but empathize with them. She allows us to see from different perspectives, how they grapple with the incredible consequences of the liberation wars and the subsequent postcolonial disruptions. Worse still, even the period of supposed peace is characterized by violence. To this end, she exposes people in their helpless states in the midst of chaos and disorder. She exposes characters who are entangled in the web of the existing power structure. She therefore wants her readers to see how extremely handicapped they are. It is in this manner that Vera successfully recruits her audience's attention. She traps them emotionally, and elicits a type of response that makes them (the readers) feel for the characters.

Apart from these, Vera wants us to admire her characters' resilience; to admire how they contend with their everyday challenges, and how they deal with the consequences of their actions. In a way, she heightens this by incorporating another crucial aspect of the characters' lives. We note that in spite of the tragic nature of their experiences, they still fall in love, they still have that inner longing to love and to be loved. In a passionate manner, Vera wants her readers not to be just concerned with the plight of the women, but to be also concerned with the plight of a whole people and invariably, with the travails of humanity in general.

\section{Conclusion}

When all aspects of Vera's way of writing are harnessed, we should accept that hers is definitely novel and unique. No doubt, her method has characteristics that are exclusively hers, thereby, making her stand apart from the crowd of other feminist writers and even other writers. 
As a feminist postcolonial writer, and in her pursuit of social justice, her struggles can be said to be operative on different levels. In the main, it is a struggle to salvage the voiceless women of Zimbabwe and women generally - to give them a voice. She also attempts to redeem the female body by suggesting that every human being has a distinct life of his own, and that this life must be valued, respected and protected. Thus, the female body must be delivered from the stifling demands of patriarchal culture and the economic exploitation occasioned by contemporary realities. With the use of striking aesthetic colours, she confronts patriarchy and upturns societal taboos. She also challenges the Zimbabwean men, seeking to redeem an entire country that has been trapped in postcolonial anarchy. Added to these, Vera persistently explores and extols the authenticity, strength and beauty that are undeniable qualities of African life and culture. She harps on the need for Africans to be rooted in their culture believing that such Africans will never be easily swayed or made to deviate from the indigenous ways of life. She is convinced that it is this type of good grounding that would assist them in resisting any opposing culture such as that of the Western colonizers. Finally, her work can be said to be a struggle to reclaim the African space that has been very badly defaced. It is her contribution to the struggle - her own distinct way of writing back to the Empire, as well as her own version of the Chimurenga Chimurenga, being a Shona word that stands for struggle. It is a struggle through her creative impulse, through the power of the pen. 


\section{References}

Bull-Christiansen, Lene. Tales of the Nation: Feminist Nationalism or Patriotic History? Defining National History and Identity in Zimbabwe. Sweden: Nordisk, 2004.

Gunner, Liz \& Kortenaar, Nei IT. "Introduction: Yvonne Vera's Fictions and the Voice of the Possible." Research in African Literatures 38 .2. (2007): 1-8.

Hunter, Eva. "War Victims and Survivors: The Expanding Vision of Yvonne Vera." Feminist Africa Review (2002): 26-32.

Lavelle, Ruth. "Without a Name: Reclaiming That Which Has Been Taken." Muponde \& Maodzwa-Taruvinga. 109-114.

Lunga, Violet Bridget. "Between the Pause and the Waiting: The Struggle Against Time in Yvonne Vera's Butterfly Burning." Muponde \& Maodzwa-Taruvinga. 191-202.

Musila, Grace, "Embodying Experience and Agency in Yvonne Vera's Without a Name and Buttery Burning”. Research in African Literatures. 38.2 (2007): 49-63.

Nwankwo, Chimalum. "Globalization, Literature and Languages: The All-Knowing Subject and the Insentient Object." CALEL. Vol. 4 (May, 2006): 32-42.

.To Trans-emote a Cosmos Yvonne Vera's Holistic Feminist Vision in Butterfly Burning." New Women's Writing in African Literature. Ed. Ernest N. Emenyonu. New Jersey. Africa World P. 2004: 43-54.

Opara, Chioma. Her Mother's Daughter: The African Writer as

Woman. Port-Harcourt: U of

Port-Harcourt P, 2004.

Samuelson, Meg. "Re-Membering the Body: Rape and Recovery in Without a Name and Under the Tongue." Muponde \& Maodzwa-Taruvinga. 93-100.

Shaw, Carolyn Martin. "A Woman Speaks of River: Generation and Sexuality in Yvonne Vera's Novels." Muponde and MaodzwaTaruvinga. 83-91.

- "The Habit of Assigning Meaning: Signs of Yvonne Vera's World." Muponde \& Maodzwa-Taruvinga. 25-35.

Vera, Yvonne. Butterfly Burning. New York: Farrar Straus and Giroux, 2000.

- Nehanda. Harare: Baobab, 1993. 
—. The Stone Virgins. Harare: Weaver P., 2002.

- Under The Tongue. Harare: Baobab Books, 1996

. Without A Name. Harare: Baobab Books, 1994 